\title{
Study of Platelet Indices and Their Interpretation in Thrombocytopenia in a Tertiary Care Hospital
}

\author{
Vani Mittal ${ }^{1}$, Munesh$^{2}$, Irbinder Kour Bali ${ }^{3}$, Sunil Arora ${ }^{4}$, Jyoti Singh ${ }^{5}$, Mohit Dadu 6 \\ 1, 2,3,4 Department of Pathology (FMHS), SGT Medical College, Hospital and Research \\ Institute, Gurugram, Haryana, India. 5, 6 Department of Public Health Dentistry, \\ Uttaranchal Dental and Medical Research Institute, Dehradun, Uttarakhand, India.
}

\section{ABSTRACT}

\section{BACKGROUND}

Thrombocytopenia may either be due to increased destruction or impaired production of platelets. Platelet count alone is not enough to determine the mechanism of low platelets. Platelet indices like mean platelet volume (MPV), platelet distribution width (PDW), platelet large cell ratio (P-LCR) and platelet crit (PCT) can help determine the cause and we aimed at finding their role and function in cases of thrombocytopenia.

\section{METHODS}

An observational cross-sectional study of 155 patients with thrombocytopenia and 71 controls was done for a period of six months in SGT Hospital, Gurugram, to determine the mechanism behind the low platelet count with the help of these indices.

\section{RESULTS}

The mean values of the platelet indices (PDW, P-LCR and PCT) were found to be higher in accelerated destruction group $(\mathrm{P}<0.05)$ in comparison to hypoproductive group, whereas, mean MPV values were higher in the former, but was not statistically significant. On comparison with the controls, both the groups of thrombocytopenia showed a statistically significant difference with $\mathrm{P}<0.005$ in all the four indices. Mean PCT values showed a highly significant difference between the two groups as well as with controls $(\mathrm{P}<0.001)$ and also the relationship of PCT with severity of thrombocytopenia showed a direct relationship which was also significant $(\mathrm{P}<0.001)$.

\section{CONCLUSIONS}

In distinguishing between the cause of thrombocytopenia i.e., hypoproductive or hyper destruction, platelet parameters play an important role. These platelet indices are easily available with the help of automated haematology analysers and can reduce the need for costly and invasive tests for evaluation of thrombocytopenia.

\section{KEY WORDS}

Mean Platelet Volume, Platelet crit, Platelet Distribution Width, Platelet Large Cell Ratio, Thrombocytopenia
Corresponding Author:

Dr. Sunil Arora,

Professor, Department of Pathology (FMHS), SGT Medical College,

Hospital and Research

Institute, Gurugram - 122505,

Uttarakhand, India.

E-mail: jugs.arora915@gmail.com

DOI: $10.14260 /$ jemds/2021/96

How to Cite This Article:

Mittal V, Munesh, Bali IK, et al. Study of platelet indices and their interpretation in thrombocytopenia in a tertiary care hospital. J Evolution Med Dent Sci 2021;10(07):435-439, DOI: 10.14260/jemds/2021/96

Submission 13-10-2020,

Peer Review 17-10-2020,

Acceptance 24-12-2020,

Published 15-02-2021.

Copyright (c) 2021 Vani Mittal et al. This is an open access article distributed under Creative Commons Attribution License [Attribution 4.0 International (CC BY 4.0)] 


\section{BACKGROUND}

Thrombocytopenia is one of the common findings among patients in a clinical setting. It is defined by platelet count below the normal values and has a significant role in both hospitalised and non-hospitalised patients. ${ }^{1}$ The counts below 1,50,000 / $\mu \mathrm{L}$ are considered as thrombocytopenia. ${ }^{2}$ The clinical manifestation varies from mild symptoms such as easy bruising / mild bleeding to massive bleeding / haemorrhage that may result in death. ${ }^{3}$

Platelets play a vital role in homeostasis and also have non-homeostatic role in angiogenesis, repairing of tissue and inflammation. ${ }^{1}$ In order to evaluate the cause of low platelet count, it is necessary to relate whether it is due to hyper destruction or impaired production. Hyperdestructive thrombocytopenia is a result of extramedullary destruction of platelets with a normal or an increased bone marrow production; causes comprise of malaria, dengue, idiopathic thrombocytopenic purpura (ITP), disseminated intravascular coagulation (DIC), haemolytic uremic syndrome (HUS). The category of impaired production is a result of primary or secondary bone marrow diseases with a decreased bone marrow production. It includes causes such as bone marrow aplasia, haematological malignancies, post chemotherapy, post radiation, hypersplenism etc. 4,5 After evaluating the mechanism behind the low platelet count, which can be helpful to the clinician in providing proper treatment to the patient. ${ }^{6}$ Bone marrow aspiration study is the gold standard for finding the cause for thrombocytopenia, but its use is restricted since it is an invasive procedure. There is also a high risk of bleeding complication associated with the procedure.

Automated cell counters are used widely these days which furnish us the valuable information of various blood cell parameters including red blood cells, white blood cells and platelets with platelet parameters. ${ }^{8}$ Recently platelet parameters like mean platelet volume (MPV), platelet distribution width (PDW), platelet crit (PCT) and Platelet large cell ratio (P-LCR) have been investigated as important platelet activation markers. All these parameters are provided by automated blood cells analysers and these indices can be correlated with platelet counts. ${ }^{9}$ Quantification of platelet indices in automated analysers has superiority over the manual estimation because it is quick, effortless and cost-effective method which also eliminates the observer bias and artifactual problems of manual method. 10

The study of these platelet indices can help establish the mechanism behind thrombocytopenia. MPV and PDW are both derived from platelet distribution curve and related to change in platelet size and shape. ${ }^{11}$ P-LCR can be used as an effective tool in distinguishing between hyper destruction and impaired production. ${ }^{12}$ P-LCR is directly related to PDW and MPV, whereas it is inversely related to platelet count. ${ }^{13}$ PCT is the volume occupied by the platelets in the blood and is expressed in terms of percentage and plays an important role in diagnosing platelet quantitative abnormalities. ${ }^{1,14}$

Platelet indices can have a significant prognostic role as early evaluation of thrombocytopenia can help reduce morbidity and mortality of patients with low platelet count. This study aims to find the usefulness of these platelet indices in initial evaluation, as their role is still not clear in patients with thrombocytopenia.

\section{METHODS}

An observational cross-sectional study was undertaken for a period of six months from September 2019 to February 2020 in the pathology laboratory at SGT Hospital, Gurugram. All the blood samples of patients which were received in K3EDTA anti-coagulated vacutainers in the laboratory, were processed within one hour of collection using the 6-part automated haematology analyser. From the analyser generated reports, platelet count and platelet parameters i.e. mean platelet volume (MPV), platelet distribution width (PDW), platelet large cell ratio (P-LCR) and platelet crit (PCT) were recorded and platelet count was reassessed by peripheral blood smear examination on Leishman stained slides in all the cases. We included 155 patients of age more than 1 year with thrombocytopenia (platelet count $<150 \mathrm{x}$ $10^{9} / \mathrm{L}$ ). Control group included 71 persons who had all the haemogram parameters within normal limits.

Approval for patient consent and patient information sheet (PIS) was obtained from institutional ethical committee since the study involved the data available in the records that was anonymised and coded so as to delink any data related to identification of the patient. 15

\section{Exclusion Criteria}

- Patients of age $<1$ year (infants) - to avoid age related changes in platelet indices.

- Patients with myelodysplastic syndrome. (MDS)

- Patients with autoimmune disorders such as systemic lupus erythematosus (SLE), Type 1 diabetes mellitus (DM), vitiligo, juvenile rheumatoid arthritis .

- Patients on anti-platelet drugs and drugs causing thrombocytopenia.

Platelet parameters were then assessed in both the groups and compared with those of the control group.

\section{Statistical Analysis}

The data was tabulated and analysed using the Statistical Package for the Social Sciences (SPSS) software 23.0 for Windows 10. Statistical mean and standard deviation were calculated for the respective parameters in the different groups. Multiple comparisons and associations were assessed using an analysis of variance (ANOVA) and Bonferroni's test was used as a post hoc test between different categories. A Pvalue of less than 0.05 only was considered as statistically significant.

\section{RESULTS}

A total of 155 patients with thrombocytopenia after informed consent were included in the study. There were $65 \%$ males and $35 \%$ were females in this study. Table I shows the agesex wise distribution of the cases with thrombocytopenia. Our age group ranged from 1 - 80 years, with more than $54 \%$ of the cases falling in the age group of 21 - 40 years. 
Comparison of the platelet indices with the severity of thrombocytopenia was also assessed. (Table II) They were categorised into 3 categories: mild thrombocytopenia with platelet count $\geq 100$ to $<150 \times 10^{9} /$ L, moderate thrombocytopenia with platelet count $>50 \times 10^{9} / \mathrm{L}$ and $<$ $100 \times 10^{9} / \mathrm{L}$ and severe thrombocytopenia with platelet count $\leq 50 \times 10^{9} /$ L. Our study showed a significant difference only in one of the platelet parameters i.e. platelet crit $(\mathrm{P}<0.001)$, while the rest of the parameters showed no significant difference.

\begin{tabular}{|cccccc|}
\hline Sl. No. & $\begin{array}{c}\text { Age Group } \\
\text { (In Years) }\end{array}$ & Male & Female & Total No & $\%$ \\
1 & $01-10$ & 8 & 6 & 14 & 9.03 \\
2 & $11-20$ & 15 & 13 & 28 & 18.06 \\
3 & $21-30$ & 32 & 14 & 46 & 29.68 \\
4 & $31-40$ & 28 & 11 & 39 & 25.16 \\
5 & $41-50$ & 9 & 4 & 13 & 8.39 \\
6 & $51-60$ & 5 & 2 & 7 & 4.52 \\
7 & $61-70$ & 3 & 3 & 6 & 3.87 \\
8 & $71-80$ & 1 & 1 & 2 & 1.29 \\
Total & 101 (65.16\%) & 54 (34.84 \%) & 155 & 100 \\
\hline \multicolumn{7}{r}{ Table 1. Age and Sex Distribution of Cases of Thrombocytopenia } \\
\hline \multicolumn{5}{r}{}
\end{tabular}

\begin{tabular}{|c|c|c|c|c|c|}
\hline $\begin{array}{l}\frac{0}{0} \\
\frac{\pi}{\pi}\end{array}$ & 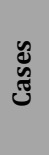 & 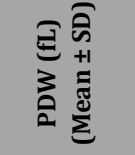 & 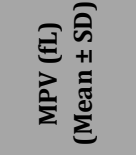 & 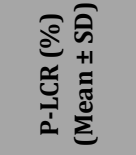 & 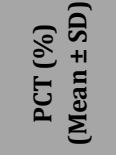 \\
\hline$\leq 50 \times 10^{9} / \mathrm{L}$ & 25 & $18.06 \pm 3.29$ & $13.21 \pm 1.07$ & $49.36 \pm 7.03$ & $0.03 \pm 0.01$ \\
\hline$>50-<100 \times 10^{9} / \mathrm{L}$ & 50 & $18.71 \pm 3.10$ & $13.48 \pm 1.18$ & $52.37 \pm 9.32$ & $0.06 \pm 0.02$ \\
\hline$\geq 100-<150 \times 10^{9} / \mathrm{L}$ & 80 & $19.02 \pm 3.32$ & $13.55 \pm 1.18$ & $52.60 \pm 9.18$ & $0.08 \pm 0.03$ \\
\hline P-value (between gro & ups) & 0.428 & 0.460 & 0.269 & $<0.001^{*}$ \\
\hline \multicolumn{6}{|c|}{$\begin{array}{c}\text { Table 2. Relationship of Platelet Indices } \\
\text { with Severity of Thrombocytopenia }\end{array}$} \\
\hline \multicolumn{6}{|c|}{$\begin{array}{l}\text { PDW - Platelet Distribution Width, MPV - Mean Platelet Value, } \\
\text { P - LCR - Platelet Large Cell Ratio, PCT - Platelet crit } \\
\text { * The mean difference is significant at the level } 0.05 \text { level. }\end{array}$} \\
\hline
\end{tabular}

\begin{tabular}{|c|c|c|c|c|c|c|}
\hline 离 & 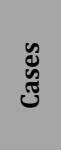 & 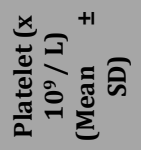 & 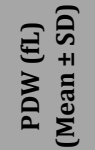 & 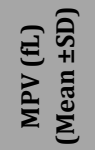 & 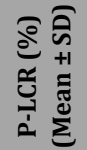 & 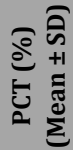 \\
\hline $\begin{array}{l}\text { A - Accelerated } \\
\text { destruction }\end{array}$ & 102 & $103.7 \pm 23.6$ & $\begin{array}{c}19.37 \pm \\
3.04\end{array}$ & $\begin{array}{c}13.66 \pm \\
1.15\end{array}$ & $\begin{array}{c}53.64 \pm \\
8.98\end{array}$ & $\begin{array}{c}0.08 \pm \\
0.02\end{array}$ \\
\hline B - Impaired production & 53 & $71.5 \pm 32.3$ & $\begin{array}{c}17.60 \pm \\
3.34\end{array}$ & $\begin{array}{c}13.11 \pm \\
1.10\end{array}$ & $\begin{array}{l}48.85 \pm \\
8.03\end{array}$ & $\begin{array}{c}0.03 \pm \\
0.01\end{array}$ \\
\hline Control & 71 & $249.7 \pm 77.5$ & $\begin{array}{c}16.01 \pm \\
4.40\end{array}$ & $\begin{array}{c}12.21 \pm \\
1.75\end{array}$ & $\begin{array}{l}41.85 \pm \\
13.63\end{array}$ & $\begin{array}{c}0.25 \pm \\
0.09\end{array}$ \\
\hline \multicolumn{7}{|c|}{$\begin{array}{l}\text { Table 3. Platelet Count and Platelet Parameters } \\
\text { According to Each Group }\end{array}$} \\
\hline \multicolumn{7}{|c|}{$\begin{array}{l}\text { PDW - Platelet Distribution Width, MPV - Mean Platelet Value, } \\
\text { P - LCR - Platelet Large Cell Ratio, PCT - Platelet crit. } \\
* \text { The mean difference is significant at the level } 0.05 \text { level. }\end{array}$} \\
\hline
\end{tabular}

\begin{tabular}{|c|c|c|c|c|c|c|c|}
\hline \multirow{2}{*}{$\begin{array}{c}\text { Platelet } \\
\text { Paramete } \\
\text { rs }\end{array}$} & \multicolumn{3}{|c|}{ Group A vs. Control } & \multicolumn{2}{|c|}{ Group B vs. Control } & \multicolumn{2}{|c|}{ Group A vs. Group B } \\
\hline & Mean & SD & $\begin{array}{c}\text { P- } \\
\text { Value }\end{array}$ & Mean & SD $\begin{array}{c}\text { P- } \\
\text { Value }\end{array}$ & Mean & SD $\begin{array}{c}\text { P- } \\
\text { Value }\end{array}$ \\
\hline PDW & 3.3623 & 0.5550 & $\begin{array}{c}\mathrm{P}< \\
0.001^{*}\end{array}$ & 1.5925 & $\begin{array}{c}\mathrm{P}= \\
0.6519 \\
0.046^{*}\end{array}$ & 1.7698 & $\begin{array}{cc}\mathrm{P}= \\
0.6081 \\
0.012^{*}\end{array}$ \\
\hline MPV & 1.4485 & 0.2109 & $\begin{array}{c}\mathrm{P}< \\
0.001^{*}\end{array}$ & 0.9057 & $0.2477 \begin{array}{c}\mathrm{P}= \\
0.001^{*}\end{array}$ & 0.5428 & $\begin{array}{cc}0.2310 & \mathrm{P}= \\
0.059\end{array}$ \\
\hline P-LCR & $\begin{array}{c}11.786 \\
4\end{array}$ & 1.6206 & $\begin{array}{c}\mathrm{P}< \\
0.001^{*}\end{array}$ & 7.0007 & $1.9033 \begin{array}{c}\mathrm{P}= \\
0.001 *\end{array}$ & 4.7856 & 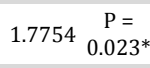 \\
\hline PCT & $\begin{array}{c}- \\
0.16430 \\
9\end{array}$ & 0.00868 & $\begin{array}{c}\mathrm{P}< \\
0.001^{*}\end{array}$ & -0.22041 & $\begin{array}{cc}0.0101 & \mathrm{P}< \\
9 & 0.001^{*}\end{array}$ & 0.05602 & $\begin{array}{cc}0.0095 & \mathrm{P}< \\
1 & 0.001^{*}\end{array}$ \\
\hline \multicolumn{8}{|c|}{ Table 4. Statistical Comparison of Platelet Parameters within Groups } \\
\hline \multicolumn{8}{|c|}{$\begin{array}{l}\text { PDW - Platelet Distribution Width, MPV - Mean Platelet Value, P-LCR - } \\
\text { Platelet Large Cell Ratio, PCT - Platelet crit } \\
* \text { The mean difference is significant at the level } 0.05 \text { level. }\end{array}$} \\
\hline
\end{tabular}

Patients with thrombocytopenia were grouped into 2 groups according to the mechanism causing low platelet count i.e. group A included those with hyper destructive causes of low platelet count and group B included causes leading to impaired production of platelets. Group A included 102 patients who were diagnosed as either of the following: dengue (28), burns (5), pregnancy (13), malaria (16), typhoid (8), disseminated intravascular coagulation (4), sepsis (6), viral infections (12), idiopathic thrombocytopenic purpura (3), or renal diseases (7). Group B included 53 patients who were diagnosed as either of the following: tuberculosis (9), chicken pox (3), deep vein thrombosis (2), chikungunya (7), megaloblastic anaemia (7), iron deficiency anaemia (10), pancytopenia (6), leukemia (5), or cirrhosis (4). Group A cases $65.8 \%$ as compared to $34.2 \%$ cases in Group B.

Table III and IV comparison and statistical analyses between the mean platelet parameters within the two groups of PCT and also the controls. It shows a significant difference i.e., $\mathrm{P}$ value $<0.05$ in PDW, P-LCR and highly significant difference i.e., $\mathrm{P}<0.001$ in mean PCT values of the three categories. Mean MPV shows slight difference when thrombocytopenia is compared with control but, there is no difference between the 2 mechanisms of low platelet count $(\mathrm{P}$ $=0.05$ ).

\section{DISCUSSION}

Thrombocytopenia is one of the common findings in many disease conditions. The major pathogenesis behind this is basically either due to decreased or impaired bone marrow production, peripheral accelerated destruction or due to increased splenic sequestration. ${ }^{1}$ Clinically, it is difficult to ascertain the reason behind the decrease in platelet count. Bone marrow studies, reticulated platelets and plateletassociated IgG have been done in the past to evaluate the reason causing thrombocytopenia, but these are costly, invasive and not easily available procedures. Recently, many studies have taken the help of various platelet indices to assess the cause of thrombocytopenia. Platelet indices are easily available as most of the automated haematology analysers calculate these values. We studied four platelet parameters i.e., MPV, PDW, P-LCR and PCT in cases of thrombocytopenia in order to interpret their importance, if any, behind the mechanism of low platelet count and also compared these values with those of the controls.

Our study included 155 patients of thrombocytopenia, who were predominantly males, which was similar in many studies. $8,9,10$ Correlation of severity of thrombocytopenia was studied with the changes in the platelet count and the platelet parameters. It was found that although as the platelet count decreases there was reduction in the mean values of all the platelet indices, only PCT showed a direct relationship with the platelet count with P-value $<0.05$. The mean PCT in cases of mild, moderate and severe thrombocytopenia was $0.08 \%$, $0.06 \%$ and $0.03 \%$ respectively. Chandrashekhar V in 2013 also justified the importance of PCT in detecting quantitative platelet disorders, where PCT can help determine the need for transfusion in cases of low platelet count.11 This is important as all the thrombocytopenia cases don't require platelet transfusion. Also mean MPV, Mean PDW and mean PLCR were least in cases with severe thrombocytopenia and 
highest in mild thrombocytopenia, but a significant difference was not observed.

Cases of thrombocytopenia were classified according to the mechanism behind thrombocytopenia, and the relationship between values of the platelet indices with the cause was examined. The mean platelet count in group A and group B was $103.7( \pm 23.6) \times 10^{9} / \mathrm{L}$ and $71.5( \pm 32.3) \times 10^{9} /$ respectively, showing significant difference between the two and with the control group $\left(\right.$ mean $=249.7 \pm 77.5 \times 10^{9} / \mathrm{L}$ ), which was also the case in other studies.8,12,13 In this study, all the four parameters showed a noteworthy difference when group A i.e. cases of hyper destruction of platelets were compared with the control group, with a high significance of $\mathrm{P}<0.001$. Group B i.e. hypo production cases on comparison with control group also showed a significant difference in mean PCT $(\mathrm{P}<0.001)$, mean PDW $(\mathrm{P}=0.046)$, mean MPV $(\mathrm{P}=$ $0.001)$ and mean P-LCR $(P=0.001)$, all indices displayed a $P$ value of less than 0.05 . Mala K.G et al. in their study on platelet count, MPV and PDW also found significant difference when the groups were compared with the control. ${ }^{8}$ Studies by Elsewefy DA et al. and Borkataky $S$ et al. also showed significant difference $\mathrm{P}=0.035, \mathrm{P}=0.017$ in mean P-LCR values of patients with hypoproductive thrombocytopenia with those of the control group.5,14,15 Significance in PCT was similar to few other studies where the mean PCT in hypoproduction group was $0.45( \pm 0.44) \%$ and in hyper destruction group was $1.16( \pm 0.48) \%$ with a $P$ value of $0.0001 .6,16$

On comparison between the two groups of thrombocytopenia, mean PDW $(\mathrm{P}=0.012)$, mean P-LCR ( $\mathrm{P}=$ 0.023) and mean PCT $(P<0.001)$ showed a difference, whereas $\mathrm{P}$ value for mean MPV was 0.59. PDW which was associated with variability in platelet size was higher in the cases of group A with the mean of $19.37( \pm 3.04) \mathrm{fL}$ as compared to $17.60( \pm 3.34) \mathrm{fL}$ in group B. Other studies also showed high PDW in hyper destruction thrombocytopenia attributing to the release of heterogenous population of platelets with anisocytosis, the reason behind it.15,17-20 While one of the study stated that due to dysplasia in megakaryopoiesis, there was high PDW in impaired production group. ${ }^{21}$ MPV is a known marker of megakaryocytic activity. ${ }^{22} \mathrm{~A}$ high value is seen when there is excessive platelet lysis as it leads to increased bone marrow production of immature platelets. ${ }^{23}$ Mean MPV was $13.66 \mathrm{fL}$ in group A as compared to $13.11 \mathrm{fL}$ in group B, which was in accordance with studies like Vinholt PJ et al., Borkataky S et al. and Reddy RS et al., 2,15,17 but the difference was not significant, which was the same in studies by Nakadate $\mathrm{H}$ et al. and Baynesti RD et al.24,25 Mean P-LCR was 53.64\% and $48.85 \%$ in group A and group B respectively, which was consistent with other studies. 14,26,27 The study by Babu E et al. showed no statistically significant difference in P-LCR value but it was also higher in hyper destructive cases as compared to impaired production. 5 PCT value measures the total platelet mass, and is dependent on MPV. ${ }^{22}$ Its value varies with platelet count and we found significantly higher values in group A and lower in group B. In group B cases, megakaryocytes also decrease in the bone marrow leading to increased tendency of bleeding manifestation, so PCT along with platelet count can prove to be a useful marker in patients with bleeding diathesis. ${ }^{28}$
On reviewing the literature, many studies have shown higher values of these parameters in hyper destructive group as compared to hypo productive group, but their significance has not been verified. ${ }^{29-31}$ As a result the cut off value has not been set by which one can place a case in one of the two categories. So further studies on platelet indices and with other markers like immature platelet fraction should be done so as to have a criterion for classifying thrombocytopenia with the help of these easily available markers.

\section{CONCLUSIONS}

Platelet crit can help assess both quantitative as well as qualitative platelet disorders and there is direct relation between PCT and platelet count. Other parameters like PDW, PLCR and MPV along with PCT can be used to interpret the mechanism behind the low platelet count, where high values of indices indicate increased breakdown of platelets in the bloodstream and low values are possibly due to impaired production due to primary or secondary bone marrow disease. These parameters need to be studied more, as their significance if recorded, can prove to be very useful in establishing causes of thrombocytopenia and will also reduce the need for the costly and invasive procedures at least in routine cases.

Data sharing statement provided by the authors is available with the full text of this article at jemds.com.

Financial or other competing interests: None.

Disclosure forms provided by the authors are available with the full text of this article at jemds.com.

\section{REFERENCES}

[1] Rodgers GM. Thrombocytopenia: pathophysiology and classification. In: Wintrobe's Clinical Hematology. 13th edn. Philadelphia: Lippincott Williams and Wilkins 2014:1058-60.

[2] Sekhon SS, Roy V. Thrombocytopenia in adults: a practical approach to evaluation and management. South Med J 2006;99(5):491-533.

[3] Khaleel KJ, Ahmed AA, Anwar MAA. Platelet indices and their relations to platelet count in hypoproductive and hyper-destructive thrombocytopenia. Karbala Journal of Medicine 2014;7(2):1952-8.

[4] Borkataky S, Jain R, Gupta R, et al. Role of platelet volume indices in the differential diagnosis of thrombocytopenia: a simple and inexpensive method. Hematology 2009;14(3):182-6.

[5] Katti TV, Mhetre SC, Annigeri C. How far are the platelet indices mirror image of mechanism of thrombocytopenia-mystery still remains? Int J of Adv in Med 2014;1(3):200-5.

[6] Parveen S, Vimal M. Role of platelet indices in differentiating hypoproductive and hyperdestructive thrombocytopenia. Annals of Pathology and Laboratory Medicine 2017;4(3):288-91.

[7] Greer P, Arber DA, Glader B, et al. Rodgers in Williams's hematology. Chap. 49. Thrombocytopenia. $8^{\text {th }}$ edn. MacGraw-Hill 2010:1101-02. 
[8] Mala KG, Bhandari BJ, Kittur SK. Paramountcy of platelet parameters in thrombocytopenia-our hospital experience. Indian J Pathol Oncol 2018;5(4):558-62.

[9] Vinholt PJ, Hvas AM, Nybo M. An overview of platelet indices and methods for evaluating platelet function in thrombocytopenic patients. Eur J Haematol 2014;92(5):367-76.

[10] Vidyadhar S. Diagnostic implication and utility of platelet indices in differentiating hypoproductive and hyperdestructive thrombocytopenia. IOSR Journal of Dental and Medical Sciences 2019;18(8):07-11.

[11] Park Y, Schoene N, Harris W. Mean platelet volume as an indicator of platelet activation: methodological issues. Platelets 2002;13(5-6):301-6.

[12] Baig MA. Platelet indices-evaluation of their diagnostic role in pediatric thrombocytopenias (One year study). Int J Res Med Sci 2015;3(9):2284-9.

[13] Babu E, Basu D. Platelet large cell ratio in the differential diagnosis of abnormal platelet counts. Indian J Pathol Microbiol 2004;47(2):202-5.

[14] Giacomini A, Legovini P, Gessoni G, et al. Platelet count and parameters determined by the Bayer ADVIA 120 in reference subjects and patients. Clin Lab Haematol 2001;23(3):181-6.

[15] ICMR. Informed consent process. Conditions for granting waiver of consent. National ethical guidelines for biomedical and health research involving human participants. Indian Council of Medical Research 2017.

[16] Vani C. Plateletcrit as a screening tool for detection of platelet quantitative disorders. J Hematol 2013;2(1):226.

[17] Negash M, Tsegaye A, G/Medhin A. Diagnostic predictive value of platelet indices for discriminating hypo productive versus immune thrombocytopenia purpura in patients attending a tertiary care teaching hospital in Addis Ababa, Ethiopia. BMC Hematol 2016;16:18.

[18] Kim MJ, Park PW, Seo YH, et al. Comparison of platelet parameters in thrombocytopenic patients associated with acute myeloid leukemia and primary immune thrombocytopenia. Blood Coagul Fibrinolysis 2014;25(3):221-5.

[19] Elsewefy DA, Farweez BA, Ibrahim RR. Platelet indices: consideration in thrombocytopenia. Egypt J Haematol 2014;39(3):134-8.

[20] Reddy RS, Phansalkar MD, Ramalakshmi PVB. Mean Platelet Volume (MPV) in thrombocytopenia. J Cont Med A Dent 2014;2(2):45-50.
[21] Farias MG, Schunck EG, Bó SD, et al. Definition of reference ranges for the platelet distribution width (PDW): a local need. Clin Chem Lab Med 2010;48(2):255-7.

[22] Khairkar SP, More S, Pandey A, et al. Role of mean platelet volume (MPV) in diagnosing categories of thrombocytopenia. Indian Journal of Pathology and Oncology 2016;3(4):606-10.

[23] Reddy RS, Khan MI, Phansalkar MD. Platelet distribution width (PDW) in thrombocytopenia. Indian Medical Gazette 2015;149(5)169-73.

[24] Xu RL, Zheng ZJ, Ma YJ, et al. Platelet volume indices have low diagnostic efficiency for predicting bone marrow failure in thrombocytopenic patients. Exp Ther Med 2013;5(1):209-14.

[25] Nehara HR, Meena SL, Parmar S, et al. Evaluation of platelet indices in patients with dengue infections. International Journal of Scientific Research 2016;5(7):78-81.

[26] Nelson RB, Kehl D. Electronically determined platelet indices in thrombopenic patients. Cancer 1981;48(4):954-6.

[27] Nakadate H, Kaida M, Furukawa S, et al. Use of the platelet indices for differential diagnosis of pediatric immune thrombocytopenic purpura (ITP). Blood 2008;112(11):4557.

[28] Baynes RD, Lamparelli RD, Bezwoda WR, et al. Platelet parameters. Part II. Platelet volume-number relationships in various normal and disease states. S Afr Med J 1988;73(1):39-43.

[29] Rajashekar RB, Mahadevappa A, Patel S. Evaluation of thrombocytopenia in megaloblastic anemia by platelet indices and megakaryocytes-comparison with hypoproduction and hyperdestruction. National Journal of Laboratory Medicine 2017;6(1):18-22.

[30] Aponte-Barrios NH, Linares-Ballesteros A, SarmientoUrbina IC, et al. Evaluation of the diagnostic performance of platelet-derived indices for the differential diagnosis of thrombocytopenia in pediatrics. Rev Fac Med 2014;62(4):547-5.

[31] Mohr R, Martinowitz U, Golan M, et al. Platelet size and mass as an indicator for platelet transfusion after cardiopulmonary bypass. Circulation 1986;74(5 Pt 2):III153-8. 